First publ. in: Trends in Ecology and Evolution 8 (1993), pp. 279-284

Since their discovery almost one hundred years ago, the adaptive radiations of cichlid fishes in the largest East African lakes have fascinated biologists. They are a prime example of explosive speciation. Among vertebrates, these species assemblages are the most species rich and the most diverse, morphologically, ecologically and behaviorally. Recent phylogenetic analyses of molecular data and refined knowledge about the geological history of the East African lakes are throwing new light on the evolutionary history of these extraordinary fish faunas.

The cichlid fish faunas of the three largest East African lakes, Victoria, Tanganyika and Malawi, are enormously diverse. Each of these lakes (Fig. 1) contains a radiation of several hundred species', almost all of which are endemic to their particular lake. These radiations make the Cichlidae one of the most speciesrich vertebrate families (Fig. 2). Their special history is highlighted by the coexistence of other families of fish that have not undergone this kind of spectacular evolution. The origin and maintenance of the cichlid species assemblages have been the subject of much research and debate ${ }^{1-5}$. Yet, the phylogenetic relationships among the endemic faunas have remained largely unresolved, since no morphological feature could be found to be characteristic of a particular radiation ${ }^{6.7}$.

Axel Meyer is at the Dept of Ecology and Evolution. State University of New York, Stony Brook, NY 11794 5245, USA.

\title{
Phylogenetic Relationships and Evolutionary Processes in East African Cichlid Fishes \\ Axel Meyer
}

The species flocks of the three lakes each contain a wide array of morphologically and behaviorally highly specialized cichlids ${ }^{1}$. Part of the reason for this diversification might be a morphological feature peculiar to cichlids $^{8}$ : a second set of jaws in back of the buccal cavity, the modified pharyngeal jaws, which are functionally decoupled from the oral jaws. This is believed to allow cichlids to become highly specialized on particular types of prey and might give them a competitive advantage over other fish that lack these modified jaws ${ }^{8}$. Some of these specializations are paralleled in cichlid species endemic to different lakes. For example, the Victoria endemic Macropleurodus bicolor and the Malawi endemic Chilotilapia rhoadesi both have highly derived dentition, jaw structures and feeding behaviors; and both prey on gastropods by crushing their shells with their oral jaws ${ }^{1,7}$.

Until recently, it was not known whether each of the assemblages is a monophyletic flock that can be traced back to a single ancestral species and consequently whether the morphological similarities between members of different flocks evolved as convergences. Alternatively, specializations could have arisen only once and could indicate polyphyletic origins for the species flocks with each of several lineages having a geographic distribution that extends beyond the boundaries of a single lake ${ }^{6.7}$. This interpretation would indicate that relationships of recent common ancestry exist among many of the members of the three species flocks ${ }^{1.7}$. Molecular approaches, especially the study of the mitochondrial genome by restriction enzyme analysis and, more recently, by DNA sequencing are providing many new insights and some surprising results ${ }^{9-11}$.

\section{Monophyly of the Lake Victoria superflock}

Lake Victoria is the youngest of the three large lakes. It started to form about 250000 to 750000 years ago', yet it contained (see epitaph below) a species flock of $>300$ endemic haplochromine cichlids. The lake had its origin from two westward flowing rivers, 


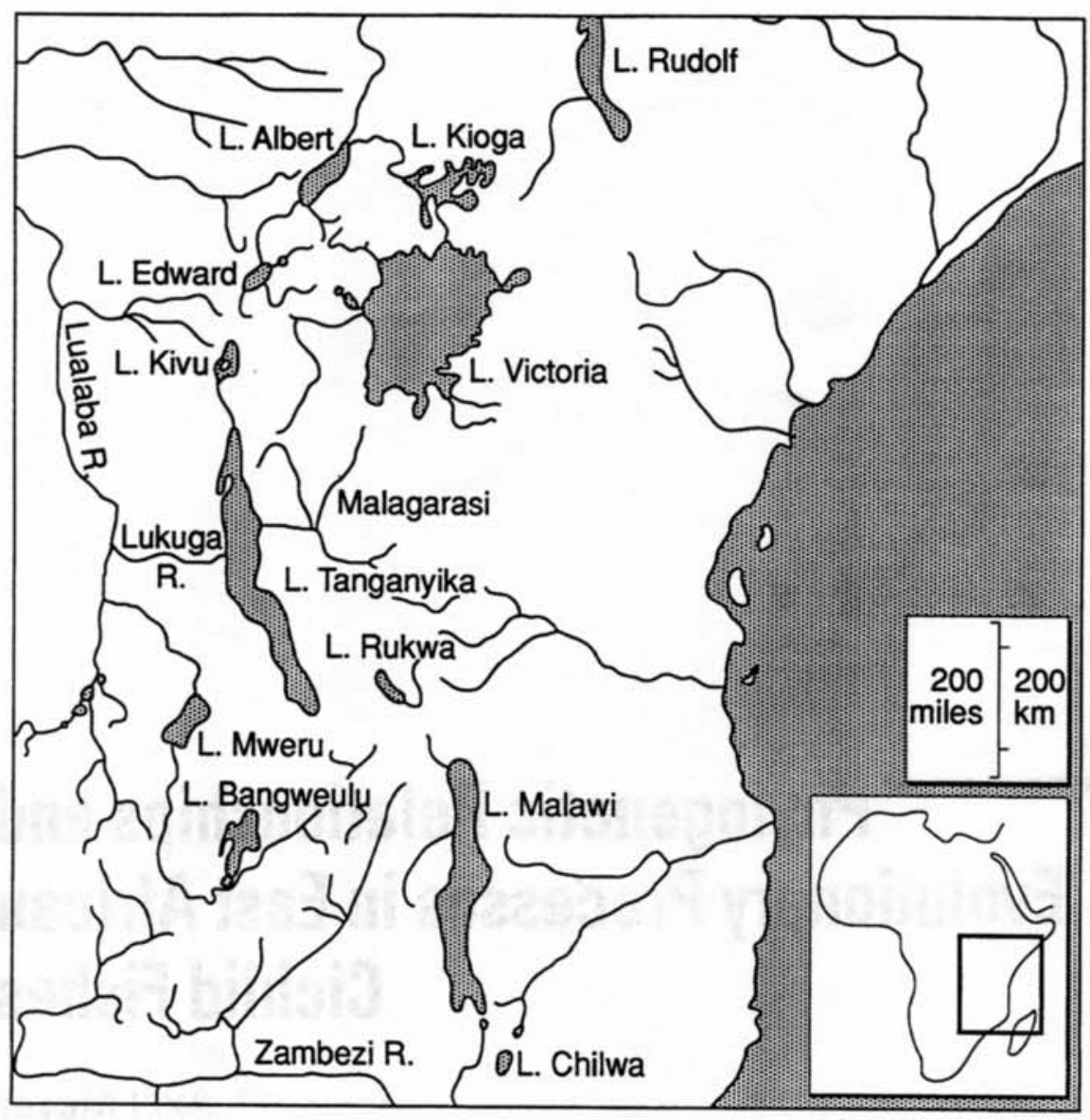

Fig. I. Geography of East Africa showing the locations of the three great lakes and the major river systems. Redrawn after Ref. $I$.

the proto-Kagera and the protoKatonga, that were blocked in the Pleistocene by the uplifted western margin of the Victoria basin. The geological history of Lake Victoria indicates that during the Pleistocene a connection existed between this lake and several smaller ones to the west of it (Lakes Edward, George, and Kivu) (Fig. 1). Therefore, the Lake Victoria flock should be considered a 'superspecies flock' extending beyond the current shores of Lake Victoria. Greenwood ${ }^{12}$ coined this term and specified three criteria for the use of 'species flock' for species assemblages: high levels of endemism, monophyly and geographic circumscription ${ }^{13}$.

Almost all of the endemic cichlids of Lake Victoria were assigned to a single genus 'Haplochromis'; now they are divided into more than $\mathbf{2 0}$ genera. Until recently, it was not known whether more than one riverine ancestral species initiated the present diversity in Lake Victoria. Among cichlid taxonomists, the tendency was to believe that the Lake Victoria haplochromine cichlid assemblage had more than one ancestor ${ }^{1}$; Greenwood argued that it should not be considered as a single species flock ${ }^{7}$. However, electrophoretic data showed that the members of this cichlid flock are extremely closely related (the mean genetic distance being only 0.006 substitutions per locus), which suggested that they might have recently arisen from a single ancestral species ${ }^{13}$.

Mitochondrial DNA (mtDNA) sequences evolve faster than nuclear DNA ${ }^{14}$. Phylogenies based on mtDNA (particularly of the fastevolving control region), therefore, can provide the finer resolution necessary for examining the evolutionary relationships among young species $^{15}$. mtDNA variation among fishes of the Victoria flock was found to be extremely small ${ }^{9}$. In fact, no variation was detected in 363 base pairs (bp) of the cytochrome $b$ gene, and only about 2-3 substitutions differentiate mitochondrial haplotypes (and, presumably, species) of Lake Victoria cichlids in $440 \mathrm{bp}$ of the control region of the mitochondrial genome?
Most of the mutations are transition substitutions rather than transversions, indicating a very recent divergence $^{16}$. More variation has been documented in the homologous portion of mtDNA in Homo sapiens than was found among 14 species of nine representative endemic genera of Lake Victoria haplochromine cichlids.

This high degree of mtDNA similarity and the earlier allozyme data suggested a very young age for this flock, probably less than 200000 years ${ }^{9,13}$ (Fig. 3). This age estimate for the species flock is younger than the lake, and supports the notion of intra-lacustrine speciation, that is, the adaptive radiation of this species flock is likely to have occurred in Lake Victoria itself rather than resulting from several immigrations of different ancestral lineages. Phylogenetic relationships within the Victoria superflock could not be established with certainty since too little phylogenetic information was contained even in the most rapidly evolving portion of the mitochondrial genome? ${ }^{9}$ Comparisons of mtDNA sequences from Lake Victoria endemics with those from Lake Malawi, Lake Tanganyika, nonendemics and riverine cichlids of East and West Africa indicate that the Lake Victoria superflock (which includes endemics from satellite lakes like Lake Edward) can be traced back to a single ancestral species $^{9.10}$ (Fig. 3). The mtDNAbased suggestion of monophyly of the Lake Victoria superflock (and the Lake Malawi flock) still holds with the inclusion of more riverine East African cichlids (A. Meyer, unpublished data).

Despite this extremely low level of genetic variation among morphologically very different species of cichlids (Fig. 2), there was only one case in which identical mtDNA haplotypes were detected in two morphotypes interpreted to be good biological species 9 . This might suggest that lineage sorting of mtDNA haplotypes was fast and almost complete even among these very young species ${ }^{15}$. These data might also suggest that the estimated number of species in Lake Victoria is supported by genetic differences and that they might indeed be reproductively isolated biological species. However, using 
mtDNA to address the question of the validity of biological species is less straightforward ${ }^{15}$. The mtDNA data provide a tentative indication that founding populations of these species might have been small and the mtDNA variability low in the progenitor population'. A more detailed characterization, with larger intraspecific sample sizes and the inclusion of nuclear DNA markers, will provide more insights into the question of the validity of the species ranks and the dynamics of speciation in Lake Victoria haplochromine cichlids (A. Meyer, unpublished).

\section{Monophyly of the Lake Malawi flock and its relationships to the Victoria flock}

Preliminary electrophoretic data determined that the endemic cichlids of Lake Malawi are very closely related ${ }^{17}$, but suggested that the Lake Malawi and Lake Tanganyika flocks are not monophyletic but share at least one lineage ${ }^{18}$. In contrast, more extensive data from mtDNA sequences indicate that the Lake Malawi species flock appears to be monophyletic ${ }^{9}$. mtDNA of the highly derived Macropleurodus-Chilotilapia species pair from Lake Victoria and Malawi (which had been used to argue for a polyphyletic origin of both flocks ${ }^{7}$ ) were compared, and it was demonstrated that these two species are not sister taxa but, instead, are more closely related to the rest of their monophyletic Victoria and Malawi assemblages ${ }^{9}$. Species from these flocks differ by at least 54 substitutions (in the 803 base pairs compared from two mitochondrial genes); hence any morphological or behavioral similarity that appears to link particular species from these lakes must now be interpreted as parallelism or homoplasy rather than as an indicator of common descent ${ }^{9}$. The Malawi and the Victoria flocks, despite being genetically distinct, are still very closely related: in the mitochondrial cytochrome $b$ gene, they differ by only $5 \%$ sequence divergence whereas congeneric cichlid species of the Neotropical genus Cichlasoma differ by up to 11\% (Ref. 9).

Within Lake Malawi two genetically distinct groups, each composed of about 200 species $^{19}$, were

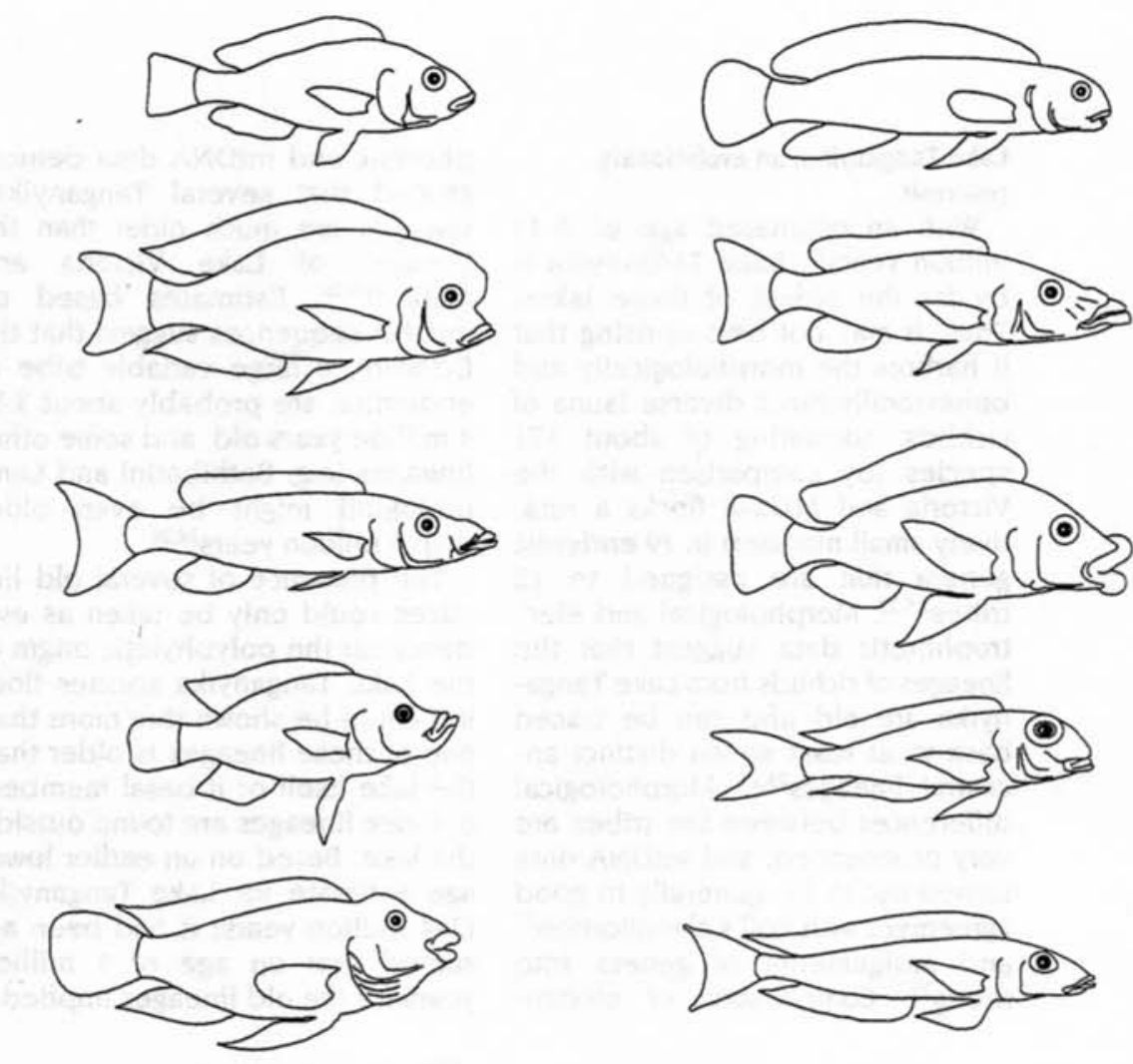

Fig. 2. Variation in body form in East African cichlid fish from Lake Victoria (V), Lake Tanganyika (T) and Lake Malawi (M). The fish are (row by row) from left top to lower right: generalized 'Haplochromis (V). Telmatochromis vittatus (T), Cyrtocara moori (M), Rhamphochromis longiceps (M), Rhamphochromis macrophthalmus (M), Lobochilotes labiatus (T). Pyxichromis parothostoma (V), Xenotilapia sima (T), Spathodus malieri (T), Xenotilapia melanogenys (T). Redrawn after Ref. I.

identified. These groups differ from each other by at least 24 substitutions $^{9}$ (Fig. 3). One group of species is largely confined to rocky habitats (the mbuna), and the second lives over sandy habitats and is composed of species that were until recently ${ }^{19}$ largely assigned to the genus Haplochromis. However, both groups can be traced back to a common ancestral species for probably the whole Lake Malawi flock, with the possible exception of the Rhamphochromis lineage ${ }^{9,20}$. Based on mtDNA sequence divergence, the age of this flock has been preliminarily estimated at around 700000 years, suggesting that this radiation took place in the Lake Malawi basin, which is 1-2 million years old ${ }^{1}$. Recent restriction analyses of mtDNA suggest that Rhamphochromis, Diplotaxodon, and Copidichromis may represent three other discrete endemic lineages $^{20}$ (Fig. 3). Furthermore, these data tentatively indicate that the Rhamphochromis lineage may be more basal than a sixth distinct lineage, Astatotilapia calliptera ${ }^{20}$ (Fig. 3). Astatotilapia calliptera, which is not strictly endemic to Lake Malawi, has mtDNA sequences ${ }^{10}$ distinct from the two major lineages and might be representative of the ancestral stock $^{10}$ (Fig. 3), which had been previously suggested by morphological data2!

mtDNA sequences tentatively identified the nonendemic Astatotilapia burtoni, a generalist species found in Lake Tanganyika and surrounding waters, to be the closest living relative of the Lake Victoria flocks ${ }^{10}$. More recently, several other nonendemic East African riverine cichlids from the Malagarasi River, the Ruahu River, Lake Rukwa and Lake Kitangiri (e.g. Astatotilapia bloyeti) have been characterized mitochondrially and are found to be even more closely related to the Victoria flock than Astatotilapia burtoni (A. Meyer, unpublished data) (Fig. 3). Some members of the widespread mainly riverine genus Astatotilapia (mitochondrially, an unnatural group) are likely to represent the body plan and lifestyle of the ancestors of the Victoria and possibly the Malawi species flocks ${ }^{10}$. 
Lake Tanganyika, an evolutionary reservoir

With an estimated age of 9-12 million years ${ }^{22}$, Lake Tanganyika is by far the oldest of these lakes. Thus, it may not be surprising that it harbors the morphologically and behaviorally most diverse fauna of cichlids, consisting of about 171 species (by comparison with the Victoria and Malawi flocks a relatively small number) in 49 endemic genera that are assigned to 12 tribes $^{1.5 .23}$. Morphological and electrophoretic data suggest that the lineages of cichlids from Lake Tanganyika are old and can be traced back to at least seven distinct ancestral lineages ${ }^{23,24}$. Morphological differences between the tribes are very pronounced, and mtDNA data turned out to be generally in good agreement with Poll's classification ${ }^{23}$ and assignments of genera into tribes $^{25}$. Comparisons of electro- phoretic and mtDNA data demonstrated that several Tanganyikan lineages are much older than the lineages of Lake Victoria and Malawi ${ }^{24-26}$. Estimates based on mtDNA sequences suggest that the Ectodini, a large variable tribe of endemics, are probably about 3.54 million years old, and some other lineages (e.g. Bathibatini and Lamprologini) might be even older than 5 million years ${ }^{24,25}$.

The presence of several old lineages could only be taken as evidence for the polyphyletic origin of the Lake Tanganyika species flock if it could be shown that more than one of these lineages is older than the lake itself or if basal members of those lineages are found outside the lake. Based on an earlier lower age estimate for Lake Tanganyika (2-4 million years) it had been assumed that an age of 5 million years for the old lineages implied a

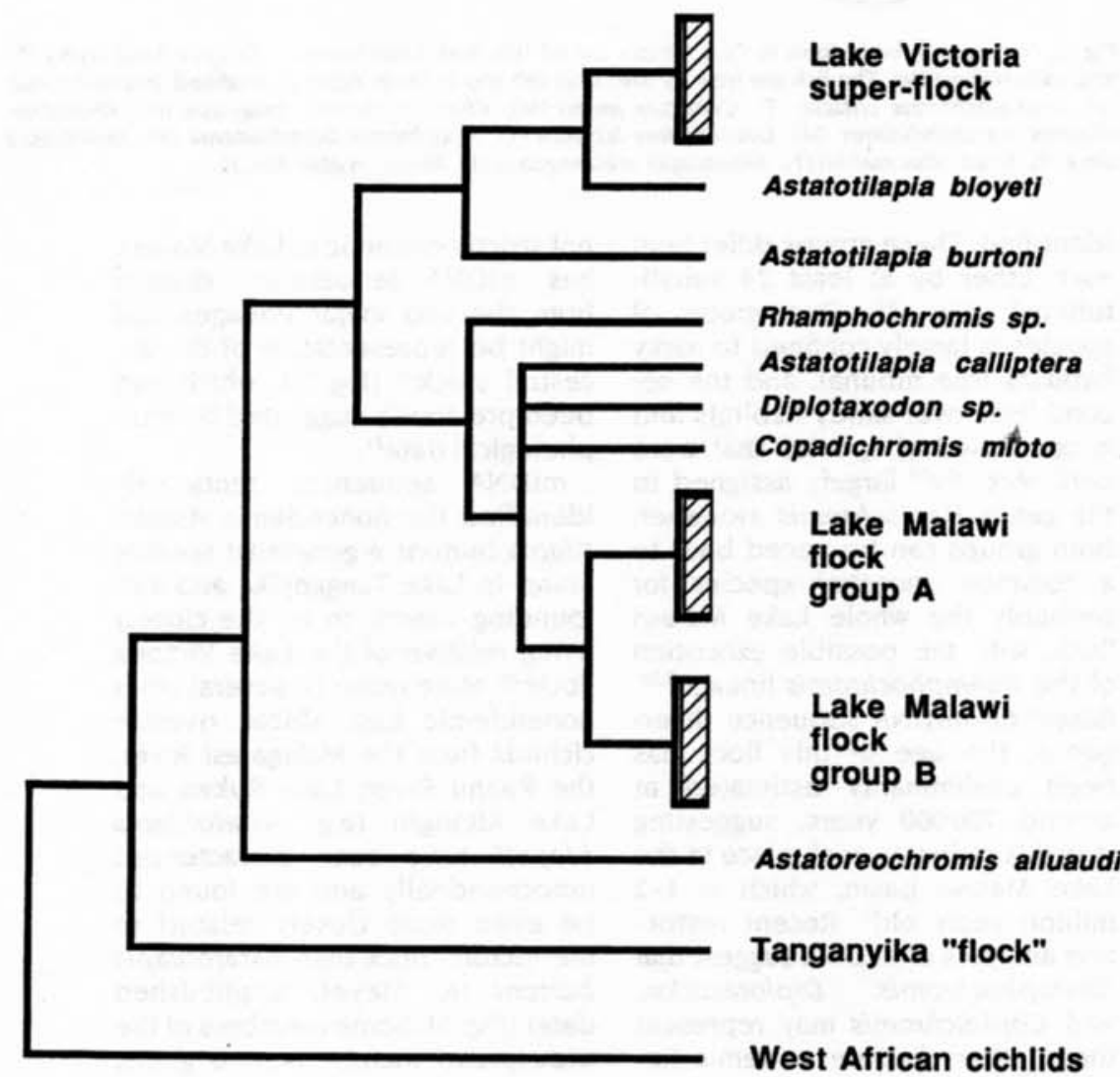

Fig. 3. Phylogenetic tree relating the three endemic species flocks of Lake Victoria, Lake Malawi and some riverine species of haplochromine cichlids from East Africa to part of the Lake Tanganyika flock (see Fig. 4). Presumed monophyletic assemblages are indicated with shaded boxes. Branches are not drawn to indicate time since divergence. Astatoreochromis alluaudi is a widespread East African species that also lives in Lake Victoria. Astatotilapia bloyeti is a generalized haplochromine (Fig. 2) that is found throughout much of East Africa and probably resembles the ancestral species of the Lake Victoria flock. Based on Refs 9,10,20. polyphyletic origin for this species flock $^{24}$. A reevaluation of the geological age of Lake Tanganyika indicated that the age of the lake is probably greater than the ages of the tribes ${ }^{22}$, which might suggest that virtually the whole Tanganyika flock could have evolved within the lake basin from a single ancestral lineage. Oreochromis tanganyicae, the only endemic tilapia of Lake Tanganyika, should be considered a pseudomember of the Tanganyika flock; mtDNA sequences suggest that its arrival to the lake is recent and that it is closely related to other tilapias outside the lake ${ }^{25,26}$. Lake Tanganyika cichlids, probably unlike those of the other two species flocks, apparently have been able to leave the confines of the lake. Several species of the Lamprologus group occur in the Zaire river; they appear be closely related to derived endemic lamprologine cichlids and are not basal lamprologine lineages (C. Sturmbauer, E. Verheyen and A. Meyer, unpublished).

Electrophoretic and mtDNA sequences suggest that the Victoria and Malawi flocks are closely related to a particular Tanganyikan tribe, the Tropheini ${ }^{24,25}$ (Fig. 4). This may not be surprising since considerable similarities between Tropheus and Pseudotropheus from Lake Malawi had been interpreted as favoring a polyphyletic origin of Lake Malawi cichlids. However, the molecular phylogeny strongly suggests that these similarities are merely homoplasies due to convergent evolution, since Pseudotropheus is genetically more closely related to all other species of Lake Malawi - even including Malawian morphological generalists that have no resemblance to Tropheus from Lake Tanganyika (Figs 3,4).

The Tanganyika flock can be viewed as a reservoir of old phylogenetic lineages that gave rise to the ancestors of the Victoria and Malawi flocks ${ }^{24}$. Lake Tanganyika does not harbor all the members and descendants of some of its endemic lineages (e.g. Lamprologini). More accurate calibrations of the age estimates for the lineages, and more work on riverine cichlids, particularly from West Africa, will be required to test the presumed polyphyly of this species flock. 


\section{Intralacustrine speciation}

Lake Victoria, with an area of $68000 \mathrm{~km}^{2}$, roughly the size of Ireland, appears to have experienced a period of almost complete desiccation as recently as 14000 years $\mathrm{BP}^{27,28}$. Numerous ponds and rivers around the margins of the lake shore might have persisted, providing refugia for fish. There was probably ample opportunity for spatial isolation within the larger lake basin, providing the necessary preconditions for geographic speciation. Amalgamation of separate faunas of several smaller bodies of water after the lake level rose again is likely to have occurred ${ }^{2}$. Geographic isolation of formerly interbreeding populations brought about by lakelevel fluctuations which split larger bodies of water into smaller ones, followed by reproductive isolation before the geographically separated populations reunited, is a likely scenario for speciation in Lake Victoria. Hence, allopatric speciation (interlacustrine between separated bodies of water) might have been an important mechanism of speciation. This possibility should not diminish the likely importance of microallopatric speciation for Lake Victoria cichlids.

Periods of aridity that led to drastic lake-level fluctuations (drops in water level of up to $600 \mathrm{~m}$ ), and splits of the single lake are also documented for Lakes Tanganyika and Malawi ${ }^{27,29-31}$. The lake topographies consist of two (Lake Malawi) or three (Lake Tanganyika) extremely deep basins (up to 704 and $1470 \mathrm{~m}$, respectively). These lake-level changes will have separated populations that once exchanged genes and will have brought into contact populations that previously did not. In species of the Tropheus species complex from Lake Tanganyika, mtDNA sequences suggest that the fluctuations might have influenced the distribution of genetic variation and probably speciation ${ }^{26}$. Genetic distances and geographic patterning of genetic variation mirror the topology of the presumed ancient lake shores during periods of low water levels ${ }^{30,31}$.

Intralacustrine speciation, probably by microallopatric speciation (through isolation by distance or appropriate habitat type), would appear to be the most important mode of speciation for all three species flocks. Tropheus, which only live over rocky habitats, from different sites in Lake Tanganyika appear to be effectively prevented from exchanging genes by discontinuities in the available habitat ${ }^{26}$ For example, long beaches or estuaries are evidently effective barriers to gene flow; large genetic differences were found between populations separated by only a few kilometers of shoreline ${ }^{26}$. Particularly in Lakes Tanganyika and Malawi, but probably also in Lake Victoria, it seems that speciation can take place in single bodies of water. It would therefore seem that physical separation of water masses is not a necessary precondition for the establishment of genetic discontinuities and speciation.

Intralacustrine speciation should not be equated with sympatric speciation and should not be interpreted as refutation of allopatric speciation models. It is often not appreciated that these lakes are vast and have extremely long varied coastlines, and that almost all endemic species have restricted geographic distributions'. Only very few species occur throughout a lake', and species are often restricted to single localities in which population size can be as small as a few hundred individuals ${ }^{32}$.
Most cichlids are poor dispersers, they are philopatric, they show homing, and males tend to defend feeding and breeding territories for several years ${ }^{33}$. All of this points toward restricted gene flow. In addition, brood sizes are small and both factors are ingredients for fast diversification by microallopatric speciation $^{34}$. Nevertheless, the close genetic relationships among Lake Victoria endemics have also been interpreted as support for models of sympatric speciation ${ }^{35}$.

Rates of speciation and morphological diversification, and the role of sexual selection

It is not clear how many species of the current flock of $>300$ species of Lake Victoria survived the episode of drying 14000 years ago. They may have survived in smaller marginal lakes, springs, or headwaters of rivers and recolonized the lake after it filled up again. It appears unlikely (but not unthinkable) that most of these species of Lake Victoria arose in less than 14000 years.

That rates of speciation in cichlids can be astonishingly fast has been known since the discovery of five endemics in Lake Nabugabo ${ }^{36}$, a small lake that is less than 4000 years old and separated from Lake Victoria only by a sand bar. These five species are believed to have

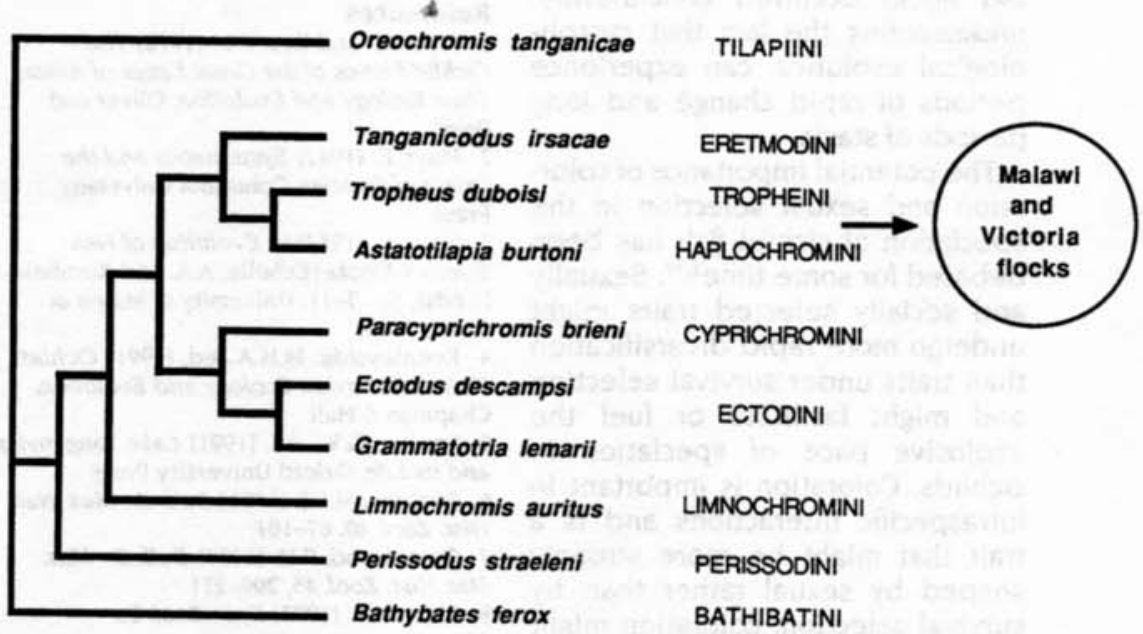

Fig. 4. Molecular phylogenetic relationships of some representative species of nine of eleven tribes (names of tribes in capitals following Poll ${ }^{19}$ ) endemic to Lake Tanganyika ${ }^{25}$. In this phylogenetic analysis both the tilapia and Bathybates were used as outgroup. Some of the members of these tribes are shown in Fig. 2 le.g. Lobochilotes belongs to the same tribe as Tropheus, the Tropheini; Spathodus belongs to the Eretmodini; Xenotilapia to the Ectodini). The sister group relationship of the endemic Lake Tanganyika tribe Tropheini to the two species flocks of Lake Malawi and Lake Victoria is indicated with the arrow and the bubble on the right and is based on Refs 24,25 . Some of the relationships of Tanganyikan tribes remain somewhat tentative (and are being tested further) ${ }^{25}$ 
close relatives in Lake Victoria that chiefly differ in the male's breeding coloration, pointing to the potential importance of sexual selection for the fast rates of speciation in cichlids ${ }^{37}$.

Even faster rates of speciation were suggested by the finding that the southern end of Lake Malawi was arid only two centuries ago and is now inhabited by numerous endemic species and 'color morphs'. These are believed to have originated during the last 200 years $^{38}$ ! This in situ speciation hypothesis seems supported by the fact that almost all endemic cichlids in all lakes have restricted geographic distributions. Ancestral genetic polymorphisms are retained across some species boundaries among some closely related species of mbuna, consistent with the extreme rates of speciation observed in Lake Malawi cichlids ${ }^{39}$.

Coloration appears to evolve quickly. In several cases, genetically closely related species of Tropheus and mbuna have very different colorations ${ }^{26.32 .39}$. Interestingly, despite pronounced variation in coloration among populations of Tropheus, this group of species has remained otherwise virtually unchanged for probably more than a million years ${ }^{26}$. The explosive speciation and morphological radiation of the Lake Victoria and Malawi flocks occurred concurrently, underscoring the fact that morphological evolution can experience periods of rapid change and long periods of stasis.

The potential importance of coloration and sexual selection in the speciation of cichlid fish has been debated for some time ${ }^{3,37}$. Sexually and socially selected traits might undergo more rapid diversification than traits under survival selection and might facilitate or fuel the explosive pace of speciation in cichlids. Coloration is important in intraspecific interactions and is a trait that might be more strongly shaped by sexual rather than by survival selection; coloration might act as a reproductive barrier without concordant morphological diversification. In Tropheus, coloration can vary tremendously among genetically closely related populations; alternatively, it can also be very similar among genetically dis- tant populations (or species) ${ }^{26}$. The importance of sexual selection in the formation of the species flocks is hotly debated - the jury is still out.

\section{Epitaph}

Regrettably, we are losing the opportunity to study the cichlids of Lake Victoria because of the introduction of the large predatory Nile perch, Lates niloticus ${ }^{40}$. This exotic species preyed upon and led to the disappearance of about 200 endemic species. Studies on the evolution of the Victoria flock may soon be pure palaeontology. This sober lesson must be used to prevent the suggested introductions of nonendemic species into Lake Malawi. Further genetic and molecular phylogenetic studies are still needed to elucidate the many remaining questions that surround the remarkable cichlid species flocks.

\section{Acknowledgements}

I thank Andrew Cohen, Irv Kornfield, Ernst Mayr, Melanie Stiassny, Paul Wilson, all my collaborators and three reviewers for valuable discussions and comments on the manuscript. Colleen Davis kindly provided technical assistance and Catherine Sexton drew Figs I and 2. This paper was prepared with partial support through grants from the US National Science Foundation (BSR9107838 and BSR-9119867) and NATO (CRG $910911)$.

\section{References}

4

I Fryer, G. and lles, T.D. (1972) The Cichlid Fishes of the Great Lakes of Africa: Their Biology and Evolution, Oliver and Boyd

2 Mayr, E. (1942) Systematics and the Origin of Species, Columbia University Press

3 Mayr, E. (1984) in Evolution of Fish Species Flocks (Echelle, A.A. and Kornfield. I., eds), pp. 3-11, University of Maine at Orono Press

4 Keenleyside, M.H.A., ed. (1991) Cichlid Fishes: Behavior, Ecology and Evolution. Chapman \& Hall

5 Coulter, G.W., ed. (1991) Lake Tanganyika and its Life, Oxford University Press

6 Stiassny, M.L.J. (1981) Bull. Br. Mus. Nat. Hist. Zool. 40, 67-101

7 Greenwood, P.H. (1983) Bull. Br. Mus. Nat. Hist. Zool. 45, 209-231

8 Liem, K.F. (1973) Syst. Zool. 22 425-441

9 Meyer, A., Kocher, T.D., Basasibwaki, P. and Wilson, A.C. (1990) Nature 347 , 550-553

10 Meyer, A., Kocher, T.D. and Wilson, A.C. (1991) Nature 350, 467-468

11 Kornfield, 1. (1991) in Cichlid Fishes: Behavior, Ecology and Evolution

(Keenleyside, M.H.A., ed.), pp. 103-128.
Chapman \& Hall

12 Greenwood, P.H. (1984) in Evolution of Fish Species Flocks (Echelle, A.A. and Kornfield, l., eds), pp. 13-19, University of Maine at Orono Press

13 Sage, R.D., Loiselle, P.V., Basasibwaki, P. and Wilson, A.C. (1984) in Evolution of Fish Species Flocks (Echelle, A.A. and Kornfield I., eds), pp. 185-197, University of Maine at Orono Press

14 Brown, W.M., George, M., Ir. and Wilson, A.C. (1979) Proc. Natl Acad. Sci. USA 76. 1967-1971

15 Avise, J.C. and Ball, R.M., Jr (1990) in Oxford Surveys in Evolutionary Biology (Vol

7) (Futuyma, D. and Antonovics, I., eds), pp. 45-67, Oxford University Press

16 Meyer, A. in The Biochemistry and Molecular Biology of Fishes (Vol. 2) (in press) (Hochachka, P.W. and Mommsen, T.P., eds), Elsevier

17 Kornfield, I. (1978) Experientia 34,

335-336

18 Kornfield, 1., McKaye, K.R. and Kocher, T. (1985) Isozyme Bull. 18, 76

19 Eccles, D.H. and Trewavas, E. (1989)

Malawian Cichlid Fishes: The Classification

of Some Haplochromine Genera, Lake Fish Movies

20 Moran, P., Kornfield, I. and Reinthal, P. Copeia (in press)

21 Trewavas, E. (1949) Proc. 13th Int. Cong. Zool. (1948), 365-368

22 Cohen, A., Soreghàn, M.J. and Scholz, C.A. Geology (in press)

23 Poll, M. (1986) Acad. R. Belg. Mem. Cl

Sciences. Collect. $8^{\circ} 45$ (2), 1-163

24 Nishida, M. (1991) Experientia 47.

974-979

25 Sturmbauer, C. and Meyer, A. Mol. Biol. Evol. (in press)

26 Sturmbauer, C. and Meyer, A. (1992)

Nature 358, 578-581

27 Stager, I.C., Reinthal, P.N. and

Livingstone, D.A. (1986) Freshwater Biol. 16, 15-19

28 Roche, E. (1991) Bull. Soc. Geog. Liège 27, 187-208

29 Tiercelin, J-I. and Mondeguer, A. (1991) in Lake Tanganyika and its Life (Coulter.

G.W., ed.), pp. 7-48, Oxford University

Press

30 Gasse, F., Ledee, V., Massault, M. and

Fontes, J.C. (1989) Nature 342, 57-59

31 Scholz, C.A. and Rosendahl, B.R. (1988) Science 240, 1645-1648

32 Ribbink, A.J., Marsh, B.A., Marsh, A.C.

Ribbink, A.C. and Sharp. B.J. (1983) S. Afr. I. Zool. 18, 149-310

33 Hert, E. (1992) Environ. Biol, Fish. 33. 229-237

34 Cohen, A. and Johnston, M.R. (1987)

Palaios 2, 426-435

35 Kondrashov, A.S. (1992) Nature

356, 752

36 Greenwood, P.H. (1965) Bull. Br. Mus. Nat. Hist. Zool. 12, 313-357

37 Dominey, W.J. (1984) in Evolution of Fish Species Flocks (Echelle, A.A. and Kornfield,

I., eds), pp. 231-254, University of Maine at Orono Press

38 Owen, R.B. et al. (1990) Proc. R. Soc

Lond. Ser. B 240, 519-553

39 Moran, P. and Kornfield, I. Mol. Biol.

Evol. (in press)

40 Witte, F. et al. (1992) Environ. Biol. Fish.

34. $1-28$ 